\title{
Socially contingent responsivity: finding a link between statistical learning and understanding the referential nature of words
}

Paper submitted in satisfaction of the preliminary examination requirement

\author{
Elena Luchkina \\ Department of Cognitive, Linguistic \& Psychological Sciences \\ Brown University \\ 2016
}

\section{Table of contents}

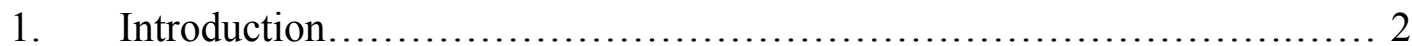

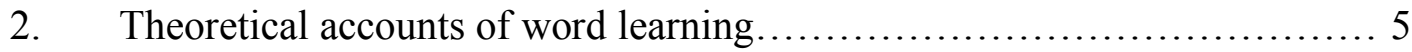

2.1. Innateness theories................................................ 6

2.2. Associative and statistical learning approaches..................... 10

2.3. Limitations of innateness theories and associative and statistical

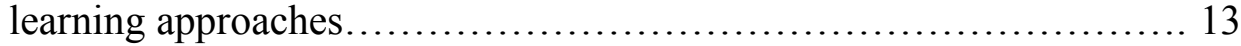

2.4. Sociopragmatic approaches................................... 16

2.5. Hybrid theories and their limitations.................................... 20

3. Contingent responsivity hypothesis................................... 25

3.1. Early sensitivity to contingent responses......................... 27

3.2. Understanding the causal link between words and other events......... 30

3.3. The mechanism of transition to the referential understanding of

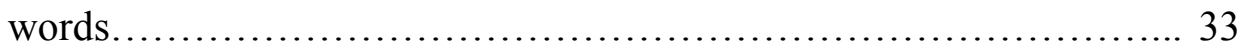

4. Effects of contingent responsivity on language development: empirical evidence......................................................... 34

4.1. Long-term effects of socially contingent responsivity on language outcomes........................................................... 35

4.2. Short-term effects of socially contingent responsivity on language

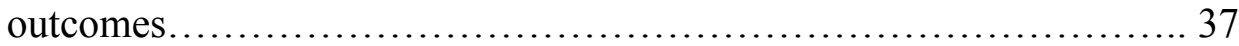

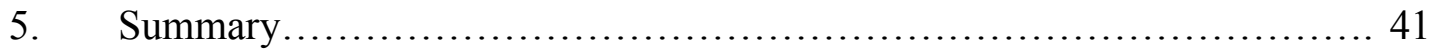

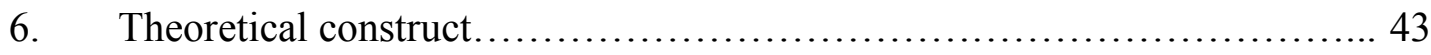

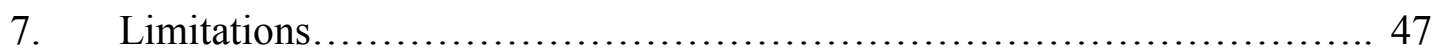




\section{Introduction}

During the first several years, children are expected to succeed on a difficult yet critically important task - acquiring language. Language enables them to receive and transmit acoustically encoded information, where sounds of speech are assigned meaning. One of the central processes of language acquisition is word learning. Words describe objects, actions, properties, abstract concepts and ideas, empowering us to navigate through physical and social environments. While many species have been shown to learn word-object associations (e.g., Lyn \& Savage-Rumbaugh, 2000; Kaminski, Call, \& Fischer, 2004), humans understand the meanings of words and know that that words refer to certain objects, actions, or ideas, not merely recognize associative pairings. A dog may learn that the word "food" is spatially and temporarily associated with feeding but there is no evidence that a dog understands that its owner is talking about food and would like the dog to retrieve its mental image of food, regardless of whether the food is currently present.

The unique ability to appreciate referential values of words have long challenged researchers and thinkers, including Aristotle who used to define words as symbols that allow people to refer to mental experiences. De Saussure (1916) proposed that words are mental representations of acoustic signals abstracted from their concrete instantiations and mapped onto mental representations of things, actions or ideas. This definition specifies that words are not simply paired with their referents in the physical world - they are linked to the representations of the physical world. With the development of psychological and cognitive sciences, the study of words and reference entered the realm of experimental research. Scientists proposed operational definitions word learning and 
their referential values. Deacon (1997) defined reference as a response to a symbol, such as a word, a sound, or a gesture. In his view, reference is derived from a cognitive action that allows one to infer reference from a symbol. Deacon emphasized the importance of studying how such responses are produced. Unlike in the case with associations, references do not imply producing the same cognitive response every time the same symbol is perceived. Word-object association would get weaker if the co-occurrence rate would decrease, while the word's referential power will not recede. Consistent with Deacon's view, Hollich, Hirsch-Pasek, \& Golinkoff (2000) pointed out that words do not need to occur close in time or space to the display of objects, actions or events that they represent. In a recent review, Waxman \& Gelman (2009) summarized critical characteristics of word learning, emphasizing that words do not merely associate but refer and that words are more than just a collection of sensory and perceptual features. Waxman \& Gelman defined the referential function of words as a link between conceptual representation and a label.

These views illustrate that despite some differences in operational definitions of reference, scientists agree that words are symbols, arbitrary links between a mental representation and a sound. Words refer to things, regardless of their proximity in time in space. A recipient knows that words are instruments of reference and not mere features of objects. Upon hearing a word, a recipient produces a cognitive response that may vary in every instance yet belong to the same set of mental representations. While a substantial amount of effort in the field is dedicated to studying the nature of representations and concepts, these topics are beyond the scope of my paper. My focus will be the 
mechanism that enables word learners to move beyond associations and establish referential understanding of words.

Adults know that words to refer to objects, actions, physical properties, unobservable particles, mental states, and even abstract ideas, such as "justice" or "singularity". What about young children and infants? While some research shows that infants aged 6-9 months already recognize word-object associations (Bergelson \& Swingley, 2012), first signs of referential understanding of words emerge around the end of the first year (e.g. Xu, Cote, \& Baker, 2005). What is the learning process underlying an apparent transition from associations to an understanding that words may refer to absent or even intangible entities?

Several theoretical accounts have been proposed to explain how infants acquire word knowledge and link words to mental representations of their referents. In this paper, I will provide a brief overview of innateness theories, associative and statistical learning approaches, sociopragmatic approaches, and a number of hybrid theories and discuss the extent, to which they can explain how infants understand that words refer. Building on these approaches, I will describe a mechanism that underlies this understanding. I propose that such mechanism is socially contingent responsivity - certain responses of adults to infants' non-distress vocalizations. This mechanism takes advantage of several learning capacities, including associative and statistical learning, recognizing social cues, and possibly certain innate mechanisms. I will discuss empirical evidence supporting my ideas and propose directions of future research that would shed more light on the development of children's ability to appreciate the referential nature of words. 


\section{Theoretical accounts of word learning}

One line of research on word learning builds on innateness, or nativist theories, which emphasize the role of innately present mechanisms and pre-existing knowledge in language learning. Some nativist hypotheses state that language development results from external triggering of innate domain-specific linguistic knowledge (e.g., Eimas, 1975). A set of abilities and perceptual sensitivity to sounds of language at birth led a number of researchers explore the idea that language is a special kind of knowledge with innately specified brain areas and mechanisms of learning. A different approach was taken by researchers developing associative accounts of word learning. Due to their behaviorist origins, which are rooted in conditioning studies (e.g., Skinner, 1948), associative accounts favor explanations that focus around associations - the knowledge that two stimuli, such as a word and its referent, tend to occur simultaneously or close in time. Sociopragmatic approaches emphasize the importance of social cues in learning (e.g., Vygotsky, 1962). Because a large portion of word learning occurs in the context of social interactions, where words play a crucial role, sociopragmatic approaches focus on mechanisms that integrate statistical, associative and social cues. More recently, researchers began to develop theories that take advantage of different families of theories. Such hybrid theories offer nuanced views and describe relatively complex models that build on a variety of learning mechanisms and assign different weights to multiple cues. In the following sections of this paper, I will review several theoretical accounts of each kind and discuss their advantages and disadvantages at explaining how children begin to understand that words refer to things. 


\subsection{Innateness theories}

Innateness theories emphasize the role of innate capacities of the mind in language learning. One of the most influential innateness accounts of language acquisition is the Universal Grammar (UG) theory first developed by Noam Chomsky (1965). Chomsky hypothesized that children's successful learning of grammar in the context of very limited input from adults (poverty of the stimulus) and absence of negative corrective evidence, cannot be solely explained by the exposure to linguistic data. Young learners succeed in acquiring generative grammar, which means that they can generate infinite number of grammatically admissible sentences. According to Chomsky, having such an ability contradicts the possibility of learning from data alone: linguistic input is finite and scarce and does not allow children to learn an infinite set of possible sentences.

Chomsky proposed a resolution to the contradiction between the impoverished linguistic input and children's advancements in language acquisition: the ability to acquire language is innate and implemented in the Language Acquisition Device (LAD). The LAD sets certain constraints limiting the range of possible grammatical systems that a child can learn. This innately specified mechanism and a set of constraints cause the world languages to converge to very similar grammars and children to achieve the same stages of language development at about the same age around the globe. Chomsky also points out that achieving those stages depends on maturational processes of the brain and on critical periods for acquiring certain types of linguistic knowledge.

Although not explicitly stated by Chomsky, the LAD that anticipates linguistic input of a certain innately specified form implies that the referential understanding of 
words is also innate. Building on Chomsky's original theory, Hurford (1989; also see Engelhardt, 2007 for review) proposed that Saussurian sign must be a part of the Language Acquisition device because linguistic data are superficial and do not make the connection between signs and their referents obvious. A language learner must know, without being aware of this knowledge, that his or her task is to acquire a system of Saussurian signs. Hurford also argued that this implicit knowledge had developed due to biological mutations that led to the emergence of Saussurian signs as a part of the LAD and granted the individuals with such mutations an evolutionary advantage in communication.

The Universal Grammar theory offers a compelling account of language acquisition as it provides a theoretical platform that can explain the role of linguistic data, specifies the mechanisms of language learning and predicts the developmental trajectory of language acquisition. The Universal Grammar account stands out as a parsimonious and comprehensive theory of language acquisition. However, despite its merits, the theory has a number of disadvantages that justify a search for an alternative explanation.

First, it is extremely difficult to conduct empirical tests of a theory that specifies not only that language acquisition is pre-determined by innate mechanisms but also that its progression is governed by the maturational processes in the brain. It is uncertain whether the developmental processes that could be observed are the prerequisite or the result of language development. Empirical tests that would help researchers dissociate between these possibilities would be unethical. Second, the large number of constraints and assumptions of the LAD (especially in Hurford's interpretation) makes it difficult to account for their emergence and weakens the evolutionary argument. It is also not certain 
whether superior communicative abilities necessarily led to advantages in mating or survival. Third, some of the more recent studies of the world's languages contradict the UG theory assumptions about language universals, such as recursion (Hauser, Chomsky \& Fitch, 2002). For example, at least some of the world's languages do not have recursion (Evans \& Levinson, 2009). These disadvantages and the lack of an explicit description of word learning mechanism which would confer referential understanding of words limit the UG theory explanatory power. While leading to significant advancements in the study of language acquisition, this theory leaves open the question about the development of children's ability to appreciate the referential nature of words.

Chomsky's argument was built upon the impossibility to reach the adult state of language development without a substantial innate component. A different approach was taken by the researchers who developed innateness hypotheses based on empirical evidence from very young infants. Early presence of behaviors that facilitate language acquisition suggest that such behaviors might be determined by innate language capacities.

One of the most documented innate capacities that may strongly influence word learning is infants' very early sensitivity to speech sounds and differences between them. Very young infants, and even newborns, prefer speech to other naturally occurring and synthetic sounds (Vouloumanos \& Werker, 2004; Vouloumanos \& Werker, 2007). Eimas, Siqueland, Jusczyk, \& Vigorito (1971) reported that infants as young as 1 month perceive sounds along the voicing continuum in a categorical manner. In addition to behavioral evidence, Dehaene-Lambertz, Dehaene, \& Hertz-Pannier (2002) conducted an fMRI investigation of 3-month-olds' brain responses to their native speech. They found 
that at 3 months, infants' cortex already shows some functional specialization, including hemispheric lateralization, suggesting adult-like speech processing early in infancy. Schultz \& Vouloumanos (2010) compared 3-month-old infants' preference for five types of sounds, including nonnative speech, rhesus macaque vocalizations, human noncommunicative vocalizations, human communicative nonspeech vocalizations, and environmental sounds. Infants listened longer to the nonnative speech, suggesting that even at a very young age, infants have already formed a preference for human speech. Investigations of infant speech perception found that not only do infants prefer to listen to speech; they can also distinguish different languages from one another. The work of Dehaene-Lambertz et al. and Schultz \& Vouloumanos, demonstrating neural and behavioral sensitivity to speech in early infancy, suggests that speech may take a special place in infant perception. Consistent with this conjecture, Nazzi \& Ramus (2003) demonstrated that 5-month-old infants could discriminate between different languages based on their rhythmic properties. This ability appeared to be independent of infants' knowledge of the native language, suggesting that the observed data could not be explained by the mere exposure to the language and are likely to have resulted from a more general sensitivity to the rhythm of speech. In addition to evidence from young infants, some empirical reports provide evidence that children become sensitive to the acoustic properties of speech even before birth. DeCasper \& Spence (1986) recruited 7.5 months pregnant women and asked them to read children's stories (The King, the Mice, and the Cheese, The Cat in the Hat, or The Dog in the Fog) twice every day until the birth of their child. The neonates were subsequently tested using the High-Amplitude Sucking (HAS) procedure and compared to a control group that did not receive prenatal exposure 
to the stories. Those infants whose mothers read the stories during their pregnancy demonstrated higher reinforcement ratios to the familiar compared to unfamiliar stories. No such difference was observed in the control group. Together with earlier results, which demonstrated that neonates prefer to listen to maternal speech to other voices (e.g., DeCasper \& Fifer, 1980), these findings support the idea that even before birth, fetuses are sensitive to certain acoustic characteristics of speech.

The reviewed experimental literature suggests that infants' early sensitivity to speech sounds might result from an innate predisposition to attend to speech. Such an early sensitivity to speech may sharpen infants' attention to linguistic input and facilitate word learning. While there is not enough evidence to support the idea that referential understanding could be driven by innate capacities, such capacities may promote associative and statistical learning. It is possible that these forms of learning combined with innate abilities, which might anticipate word input, could explain how infants begin to understand that words have meanings and refer to things.

In the next section, I will review some of the associative and statistical learning accounts and discuss their capacity to explain referential understanding of words.

\subsection{Associative and statistical learning approaches}

By attending to speech and tracking its co-occurrence with events in the environment, infants may start associating some acoustic information with those events. In doing so, they may rely on statistical regularities in co-occurrences that they observe. Empirical work by Saffran, Aslin, \& Newport (1996) showed that infants possess an ability to parse continuous streams of speech into segments based on statistical 
regularities. They exposed 8-month-old infants to a stream of fluent speech and found that just after 2 minutes of such exposure participants were able to segment the stream into words. In their study, the words were 3-4-syllable nonsense sequences presented to infants in random order. The probability of transition from one syllable to another was 1.0 within words and 0.33 between words. This statistical information was sufficient for infants to segment the sequence of syllables into words and dishabituate to nonwords (syllables in a different order than before). Consistent with these results, Mattys, Jusczyk, Luce, \& Morgan (1999) found that 9-month-olds attend to distributional cues both within and between words and use a combination of prosodic and phonotactic cues to determine the location of word boundaries. Saffran, Johnson, Aslin, \& Newport (1999) replicated this effect with tones, corroborating the idea that statistical inferences might play a significant role in language acquisition and that this mechanism is available from very early in infancy. Furthermore, infants do not use probabilistic cues only to determine word boundaries but also to discriminate between lexical and grammatical words (Werker, Shi, \& Morgan, 1999). They recognize single words and may pair them with likely referents. For example, 8-month-olds (Jusczyk \& Hohne, 1997) and even 6-montholds (Shukla, White, \& Aslin, 2011) extract words from a continuous stream of speech and remember those words for extended periods of times. They succeed on this task even in environments with noisy data, such as a usual home or a daycare, where infants are exposed to a lot more ambiguity than in a laboratory setting. Statistical learning mechanisms help them strip away noise and learn correct associations by tracking crosssituational statistics of word-referent co-occurrences (Smith, Suanda, \& Yu, 2014). For 
example, 5-month-olds were shown to recognize their own names uttered by an unfamiliar speaker (Mandel, Jusczyk, \& Pisoni, 1995).

These empirical findings indicate that statistical and associative mechanisms are present very early in development and might drive infants' lexical learning, allowing them to parse continuous stream of speech into segments, distinguish between different categories of segments, and to associate such segments with co-occurring events. In line with this conjecture, Plunkett, Sinha, Møller, \& Strandsby (1992) proposed a connectionist model of lexical learning. They argued that that symbols (of which a word is one kind) emerge as associations between labels and clusters of stimuli and form a layer of symbolic representations tightly interconnected with sub-symbolic representations. Plunkett et al. propose that symbolic meaning emerges from categorization of stimuli and formation of hidden units in the network that connects categories with labels. While the model performs consistent with this definition of symbolic meaning and follows some behavioral patterns exhibited by children, it is not clear whether the model would account for the development of referential understanding of words. In my view, symbols are not only paired in some way to a category but are understood as a tool used to refer to such a category in communication. It is possible that some of the hidden layers in the network encode this form of pairing. A test should be conducted to investigate the capacity of such a model to accommodate referential understanding of symbols. 


\subsection{Limitations of innateness theories and associative and statistical learning approaches}

Innate sensitivity to speech sounds may draw infants' attention to speech acts, cooccurrence between events and words facilitates associative learning and categorization (e.g., Waxman \& Markow, 1995; Ferry, Hespos, \& Waxman, 2010), and perceptually based categorization drives infants' ability to generalize labels to various instances of events. Research work I have discussed so far demonstrates that very young infants can master nuanced forms of pairing, parse continues streams of speech into segments and remember those segments and associations. With such a toolkit available from a very early age, infants can accumulate large vocabularies and learn to extract words from utterances. These mechanisms might work in concert to launch the process of language acquisition and guide it until more advanced mechanisms (e.g. syntactic bootstrapping) become available. However, none of the reviewed work provided empirical evidence that infants in the first year of life understand the referential nature of words. If innate learning capacities combines with statistical and associative mechanisms were sufficient to initiate referential word learning, infants would exhibit behaviors consistent with such an understanding. A number of studies that investigated early word comprehension suggest that while associations and even generalizations of labels may emerge in the first six months, referential understanding of words does not become evident until the end of the first year.

For example, Bergelson \& Swingley (2012) investigated 6-9-month-olds’ knowledge of common nouns. They recorded parents utter phrases that ask infants to look at one of the pictures (e.g., "Look at the apple") and played those utterances to infants, 
simultaneously showing pairs of images in "language guided looking" task. The utterances contained names of objects depicted on one but not the other picture. The authors found that both younger and older infants showed successful recognition of many common nouns. This work demonstrates that infants at 6-9 months do not just have some knowledge of words but also posses the ability to make certain generalizations of object labels to two-dimensional depictions of those objects. Could these results signal that at 69 months infants have developed referential understanding of words or could they be explained by perceptual mechanisms? DeLoache, Strauss, \& Maynard's (1979) study suggests that generalizations early in infancy are based on perceptual similarities between 3-dimensional and 2-dimensional stimuli. They used novelty-preference technique to demonstrate that 5-month-old infants recognize 2-dimensional pictures, both colored and black-and-white, of objects to which they were familiarized and looked significantly longer. French, Mareschal, Mermillod, \& Quinn (2004) modeled and replicated the results of a model with empirical data, showing that 3-4-month-olds' categorization of animals is driven by a bottom-up perception-based process. The evidence from DeLoache et al.'s and French et al.'s work leads to the conjecture that at 6-9 months, infants may still be relying on associative mechanisms in word learning, even when they generalize labels of 3-dimensional objects to their 2-dimensional depictions.

Bergelson \& Swingley (2015) replicated and extended their earlier findings, reporting additional evidence that 6-9-month-olds are unlikely to possess the ability to appreciate the referential nature of words. They used a similar procedure, except that this time infants saw simple scenes involving objects and actions on video, which enabled the authors to test infants' knowledge of both nouns and verbs. Younger infants (aged 6-9 
months) performed poorly on trials with common verbs compared to common nouns, whereas older infants (aged 14-16 months) were consistently above chance on both verbs and nouns. These results may indicate that until the beginning of the second year, infants' word learning is driven by associative mechanisms. Verbs are less likely to be uttered in the same labeling contexts as nouns. Rather than pointing or otherwise directing infants' attention to action and labeling it, parents are more likely to embed words in imperative sentences or questions, in which case referent actions are not displayed. This evidence corroborates the idea that younger infants' word knowledge is driven by associative mechanisms.

Some studies suggest that even by 12 months, infants may not achieve referential understanding of words and treat them as perceptual features of object categories, similar to their shape or texture, relying on the statistical and associative mechanisms. For example, Gliozzi, Mayor, Hu, \& Plunkett (2008) investigated the impact of labels on infant visual categorization. They developed a computational model following up on the results reported by Plunkett, $\mathrm{Hu}, \&$ Cohen (2008), where the authors demonstrated that labels might facilitate and also interfere with categorization in 10-month-old infants. The model was based on self-organizing maps with visual and auditory features and predicted infants' looking time at images. The model replicated the empirical findings without any explicit teaching, which suggests that infants, like the model, might treat object labels as perceptual features and not symbols referring to objects. These associations between categories and labels can account for the results reported by Bergelson \& Swingley (2012), which would suggest that their findings should not be interpreted as strong evidence of referential understanding of words at 6-9 months. 
The reviewed work on lexical learning and comprehension in infancy does not provide evidence in support of early understanding of words as references. Innate learning capacities, associative and statistical mechanisms available early in infancy do not appear to be sufficient to develop the ability to recognize that words refer to things and not simply perceptually paired with their referents. The question remains, what drives the development of such an understanding and when does this transition happen? How do infants learn that a word may refer both to present and absent objects?

\subsection{Sociopragmatic approaches}

The lack of fully specified innate, associative, or statistical mechanism that would explain the development of referential understanding of words drew researchers' attention to sociopragmatic theories. Sociopragmatic approach to word learning emphasizes the role of social cues and social contexts in language acquisition. Because language is a social skill and serves communication purposes, sociopragmatic theories propose that the mechanism underlying referential word learning must at least in part be grounded in social mechanisms (Nelson, 1988; Carpenter, Nagell, \& Tomasello, 1998; Akhtar \& Tomasello, 1998; Tomasello, 1992). Sociopragmatic investigations suggest that the first birthday marks an important milestone in infant social and lexical development. Around 12 months infants' social development undergoes significant changes. At this age infants begin to show more sophisticated understanding of their social environment and the role of language in social interactions. Infants follow the gaze of others, reliably engage in joint attention and attribute intentionality to the behaviors they observe. For example, Gergely, Nadasdy, Csibra, \& Biro (1995) demonstrated that 12-month-olds begin to interpret goal-directed actions as intentional and causal. Programmatic investigations of 
social development demonstrate that the beginning of the second year marks a qualitative shift in multiple social competences. Carpenter et al. (1998) conducted longitudinal analyses of social behaviors of a group of 24 infants aged 9 to 15 months. They observed a significant increase in attention following between 10 and 11 months with the mean age of emergence at 11.5 months. Infants' imitative learning and the use of declarative gesture significantly increased between 11 and 12 months. Between 12 and 13 months, infants started to attempt to redirect adults' focus of attention. Carpenter et al. also found that infants' joint engagement with their mothers significantly increased at every onemonth interval between 9 and 12 months. These findings illustrate that by 12 months infants' social development reaches important milestones, which may complement already present associative and statistical mechanisms and play a significant role in the development of referential understanding of words. Vouloumanos, Onishi \& Pogue (2012) findings support this conjecture showing that 12-month-olds have a sophisticated understanding of goal-directed behavior, and understand that speech communicates intentions, even if the final goal is not directly observable. Infants were also shown to recognize speech but not non-speech vocalizations as communicative and to judge about the function of speech depending on the structure of social interactions (Martin, Onishi, \& Vouloumanos, 2012).

These empirical findings support the hypothesis that infants' learning capacities might be substantially enhanced by newly available understanding of the social world and increased attention to social cues around the first birthday. Consistent with this view, Pruden, Hirsh-Pasek, Golinkoff, \& Hennon (2006) found that before 12 months, infants' word learning is driven by perceptual salience of objects rather than social cues. They 
propose that the developmental shift happens around the first birthday when infants begin to incorporate sophisticated social information into word learning. Pruden et al. found that unlike 10-month-olds, infants at 12 months were sensitive to social cues.

Gliga \& Csibra (2009) reported more explicit evidence of the emerging referential understanding of words around the first birthday. They investigated the ability of 12-13month-olds to understand the referential nature of deictic gestures and words. Using a version of the violation of expectation procedure, Gliga \& Csibra demonstrated that infants do not simply associate objects with their names but expect a speaker to refer to an object. In the "single-source" condition, infants saw a video, in which a woman named a hidden object and pointed at it. In the "dual-source" condition, a man silently gazed at the hidden object, while a recording of a woman's voice naming the object was played, and then pointed at the hidden object. Infants looked longer if the object was revealed in a different location than was cued in the single-source but not in the dual-source condition, suggesting that infants don't simply associate an object with a label. They use other additional cues (gaze, pointing) to infer that a person has referential intentions. When cues provided by a person and a disembodied voice appeared at the same time, it was not clear whether they referred to the same object, which was indicated by the lack of significant difference in looking time.

Xu et al. (2005) used a search task to investigate whether 12-month-olds understand words as references and found that infants recognized that words could refer to hidden objects. Xu et al. examined whether the act of labeling, combined with intentional and referential cues, would lead to differences in search behavior depending on the number of labels. Experimenter presented infants with an opaque box, looked 
inside it and labeled either one or two objects. The box always contained only one object. Infants searched significantly longer when the experimenter labeled two objects. These data provide additional evidence that by 12 months, infants exhibit the first signs of referential understanding of words.

Notably, around the same time as infants start to treat words as references, they also make their first steps in word production and exhibit accelerated word-object mapping. Woodward, Markman, \& Fitzsimmons (1994) demonstrated that 13-month-olds learn novel object labels after just 5 minutes of exposure and retain this knowledge after a 24-hour delay. Werker, Cohen, Lloyd, \& Casasola (1998) found that 14-month-olds learn new object labels after a few seconds of exposure.

In sum, empirical evidence from sociopragmatic studies, using different research paradigms, converge to the idea that infants begin to incorporate sophisticated social judgments in word learning around their first birthday. This additional learning tool may build on earlier available mechanisms, leading to qualitative changes in word learning and possibly facilitating the understanding that words are used to refer to things. In agreement with this conjecture, Nazzi \& Bertoncini (2003) linked the vocabulary spurt observed in the second year of life to the change in word learning mechanism that drives the shift from associative to referential understanding of words.

The question that follows from sociopragmatic evidence is what social mechanism might be interacting with other learning capacities to result in infants' transition from not knowing to knowing that words refer to things. For example, more complex social cues, which infants begin to recognize by the end of the first year, may serve spotlights directing infants' attention to linguistic input. If this is the case, 
referential understanding might be developing as a natural progression of learning more and more associations and repeated language exposure in various contexts. Alternatively, social cues may modulate the way infants perceive linguistic input and lead to a different form of encoding. Neither associative learning theories, nor sociopragmatic approaches I have reviewed so far provided a satisfactory explanation of the development of referential understanding of words. In the next section I will review a set of hybrid theories, which used combinations of cues and mechanisms and explored the role of different cues in referential word learning.

\subsection{Hybrid theories and their limitations}

Following theoretical debates (e.g., Golinkoff et al., 2000) and heterogeneous empirical findings landing support to competing approaches, a number of hybrid theories have been developed to bring these approaches together. The picture that emerged from my literature review is broadly described by the transition from innate capacities and associative mechanisms, aided by sensitivities to statistical information, to more complex mechanisms that become incorporated into word learning as infants' social development meets critical milestones. In the next section, I will review several theories bridging different theoretical approaches to word learning and discuss the mechanisms of transition that they implicate.

One of the most cited models that explains word learning from its earliest forms to relatively sophisticated and socially cued processes is the work by Hollich et al. (2000). They proposed a hybrid theory, which proposes a holistic view of word learning in early childhood combining sociopragmatic, associative, and constraint theories. The authors used the development of reference as a test case. Hollich et al. hypothesized that 
reference develops from an immature to the mature state and that infants begin to appreciate reference at around 12 months. The model posits that children are sensitive to attentional, social and linguistic cues (e.g., the rules of syntax) to which they assign different weights over the course of early word learning. All cues are present whenever language is heard, and the key question is how the learner uses those cues to guide his or her word learning. Hollich et al. proposed that infants start with relying on attentional cues, like perceptual salience, and later transition to incorporating social and linguistic cues. Statistical information about the reliability of cues affects the weights that infants' assign to different cues. The authors emphasize the role of maturation process that allows new principles and constraints to emerge. The central mechanism by which infants assign and re-assign weights to different cues is grounded in their cognitive development. This model provides a compelling view that might be an accurate description of how infant word learners shift weights assigned to various cues. In this view, around the time infants' start appreciating social cues, they gradually transition from associative to referential word leaning. However, I argue that the mechanisms described by this model are underspecified. The model relies on the idea that cognitive development facilitates maturation processes that drive the transition from associative learning to incorporating social cues. What remains underspecified are the cognitive advancements that grant infants access to more sophisticated tools and enable them to use available instruments to create better tools for word learning. While this model provides a detailed and likely accurate description of the cue selection, in which infants engage when learning new words, it leaves open the question of how infants undergo the transition from using mostly associative to using social cues. 
Another model was proposed by Regier (2005) who argued that the transition from associative to referential word learning does not require any change in the mechanism. This model relies on an associative exemplar-based account of word learning and describes a feature-selection process by which individual word-meaning pairs transform into clusters of form (word) and clusters of meaning. Regier makes an assumption that the difference between association and reference is in the number of exemplars of form and the number of exemplars of reference that are tied by a single link. Regier states that the apparent qualitative transition is in fact the result of gradual learning about the aspects of words that are relevant to communication. While I agree that certain aspects of infants' word learning progress can be attributed to associative processes, the model does not explain how infants understand that communication is the function with respect to which word learning needs to be optimized. I hypothesize that understanding this function is tightly connected to the understanding that words refer to things, which leads to a loop argument in the context of this model. In order to understand that words serve as instruments of communication, it is necessary to understand that words are units of meaning, which requires that infants know that words refer. The idea that words communicate is embedded in the assumptions of the model. For this assumption to be valid, there either needs to be empirical evidence indicating that such an understanding is present in the early infancy, or a mechanism describing its development.

Yu \& Ballard (2007) developed a probabilistic network for encoding multiple sources of information. The model combines multiple cues and computes association probabilities for multiple word-referent pairings. The authors state that social cues play 
the role of attentional spotlights that draw infants' attention to specific parts of a scene and facilitating referential disambiguation. Yu \& Ballard conclude that their model provides an integrated view that accommodates both associative and sociopragmatic views on word learning. This model indeed takes advantage of both worlds and describes ways in which infants might resolve referential ambiguity in word learning contexts. However, in my view, this is an extended version of a statistical learning model that uses social cues to determine weights of possible word-referent associations. The model does bring the two accounts together, yet it does not address potential changes in the mechanism underlying word learning at different ages.

A similar view was proposed by McMurray, Horst, \& Samuelson (2012), who focused on creating model that would use associative mechanisms to resolve referential ambiguity. They argued that the mechanism underlying referential learning of words is consistent with associative accounts and does not change over time. Similar to Regier and Hollich et al., they assert that the change is in the information used in word learning and not in the mechanism. McMurray et al. describe a model tested on a neural network that can learn new words under the conditions of referential ambiguity and learn multiple names for categories. The model emphasizes the development of the ability to recognize and to use new words, as opposed to studying words as a type of knowledge. However, the authors omit to explain what it means for a word to be conceived as a reference. They acknowledge the discussion in the field but dismiss the argument as a straw man, emphasizing that associative theories consider representations to be the basis of association. Yet their model does not elaborate on the nature of such representations and is build upon a set of assumptions about representations. While McMurray et al. pose that 
a child learns to use the information relevant to word learning and referential disambiguation, it is not clear how and why this learning occurs. They contrast their account with previous work and particularly with the arguments about shift in the word learning mechanism. I suggest that this contrast is based on a superficial interpretation of non-associative accounts. Associative mechanisms aren't said to cease as social cues become available, rather associative mechanisms are supplemented by social cues. The authors reject sociopragmatic arguments without proposing a viable alternative to the learning mechanism that would lead to the development of reference. Similar to Regier (2005) model, the claims of this model would be better substantiated by empirical evidence validating its assumptions.

A recent investigation by Yurovsky \& Frank (2015) offered an alternative view. While it is broadly consistent with the ideas of Hollich et al. (2000), the authors explicitly emphasize the role of domain-general cognitive processes that drive the inclusion of social cues into word learning and a potential shift from associative to referential understanding of words. This shift does not happen because of the predictive power of social cues - it depends on memory and attention capacities. Eye-tracking data from two experiments backs up the authors' claim and shows that the differences in relative weights of social and perceptual cues do not explain the ability to disengage from a speaker and focus on the target object (which strengthens with age). Yurovsky \& Frank showed that the developmental changes in looking behavior were driven by disengagement from the social stimulus as opposed to disengagement from perceptually more salient stimuli, as would be predicted by a model similar to Hollich et al. The authors conclude that it is the development of lower level process that drives the observed 
changes in infants' and children' looking behavior. In my opinion, this explanation is more insightful than previously described models that attempted to integrate sociopragmatic and associative accounts of word learning. The authors' conclusion requires further investigation, as it is not clear whether the proposed hypothesis about memory and attention mechanisms is true. Yet, by highlighting the role of domaingeneral cognitive development they laid out a foundation for a new line of investigation. This line of research would explore the development of cognitive abilities that underlie the shift from word learning dominated by associative mechanisms to incorporating social cues. Such a shift may facilitate the leap from associative to referential understanding of words. Further work is necessary to determine what exactly develops during early childhood that allows children to make such a leap.

\section{Contingent responsivity hypothesis}

In the previous two sections of this paper I proposed that children's word learning begins as an association-based statistical learning process and then transforms into a more complex from of learning that relies on the understanding that words refer to things. I've reviewed several families of theories that attempt to explain why and how this transformation might occur. Innateness theories, associative accounts, and statistical learning accounts have been developed to explain how infants begin to attend to linguistic information, to parse it into separate units, and to associate those units with potential referents. Sociopragmatic theories emphasized the temporal contiguity of the apparent emergence of referential understanding of words and reaching important milestones in social development. Hybrid theories attempted to bridge previously 
developed accounts to construct a more comprehensive view of word learning in infancy and the mechanisms driving it at different stages of development. My review reveals that none of the existing theories specified a mechanism that might drive the transition from associative to referential word learning. While some theories describe a shift in weights assigned to different cues available to a novice word learner, they do not explain why and how those shifts occur. To fill in this gap in theories of word learning, I will develop a hypothesis building on Yurofsky \& Franks' work and explain the transition from associative to more complex forms of word learning.

I hypothesize that the process underlying the advancements in word learning observable by around 12 months is grounded in the emerging understanding of causal relations between words and events in the world. Sobel and Kirkham (2006) demonstrated that infants as young as 8 months might be capable of causal inferences that go beyond simple associations, register conditional independence of events and can at least understand predictive relations between events. Through this understanding infants realize that the use of words has social and other consequences in their environment. This understanding drives the realization that words are not simply paired with objects, actions or ideas but are used to refer to them and serve communicative purposes. Once infants reach this realization, their attention to social cues in word learning increases because such cues help them remember a word, encode the context in which it is used, and hypothesize about potential consequences of utterances.

For such a realization to occur it is necessary that infants consistently observe situations displaying the causal link between words and their consequences. This link has been described in the literature as "socially contingent responsivity" - a phenomenon 
observed in most human interactions: an action or an utterance of an interlocutor is contingent on actions or utterances of the other interlocutor. To develop my hypothesis, I will review empirical evidence from a number of studies and discuss socially contingent responsivity as a theoretical construct.

\subsection{Early sensitivity to contingent responses}

Existing work in the field suggests that infants are sensitive to socially contingent responsivity from a very young age (e.g., Bigelow, 1996). This sensitivity guides their social development and participates in fine-tuning of their social skills, including language. Many empirical investigations demonstrate profound effects of exposure to socially contingent interactions on word learning and language development more broadly. Csibra \& Gergely (2009) hypothesized that very young infants are already sensitive to certain communicative signals and use those signals to direct their learning activity. Csibra (2010) defined several kinds of such signals: eye contact, infant-directed speech and contingent responsivity. Contingent responsivity is described in terms of turn taking and timing of communicative actions. This form of ostensive communicative signaling might be critical to establishing a communicative interaction: without contingency, determining targets of communicative acts and intentions would be particularly challenging. Socially contingent responsivity therefore guides a wide range of social behaviors and establishes the expectation of feedback contingent on an action, such as an utterance.

In the past two decades, developmental researchers produced widely replicated data showing that young infants are highly sensitive to contingent social responses from others. One of the first contingent interactions experienced by an infant is breast-feeding. 
Typically, an infant does not suck on mother's breast continuously. There are intervals when he or she ceases to suck and later continues. As an infant ceases to suck, a mother encourages sucking by jiggling him (Kaye, 1977). The infant then resumes sucking after jiggling stops. Csibra describes this form of interaction as a "proto-conversation". This view is supported by experiments conducted by Masataka (2003) who showed that infants do not only react to caregivers' actions but also intentionally seek their responses. Bigelow (1996) showed that 3-to-5-month-olds are sensitive to socially contingent responses, prefer socially contingent strangers, associate the level of contingency with personal identities, and retain this association over time. Bigelow \& Rochat (2006) later demonstrated that infants as young as 2 months engage in contingent face-to-face interactions with adults and are also sensitive to levels of social contingency. In their study infant-mother or infant-stranger dyads were brought to a laboratory space and interacted for 5 minutes. Adults were told to engage in a normal interaction with the infant. Bigelow \& Rochat found that infants were less responsive to strangers if their level of contingency was either higher or lower than the infants' mothers. These findings provide additional evidence that infants are sensitive to social contingencies from an early age and suggest that socially contingent responsivity might not only facilitate interactions but also antecede infants' understanding of communication.

Infants notice contingent responses in their interactions with caregivers and display preferences for certain levels of contingency. In addition, they themselves respond to their mothers' vocalizations and smiles in a contingent manner. This behavioral pattern emerges early in infancy and plays an important role in caregiverinfant mutual attunement. Bigelow \& Power (2014) tracked a group of infants throughout 
the first 3 months and demonstrated, using the still face paradigm, that the level of maternal vocal responsivity at 2 months influenced infants' responsivity at 3 months of age. Kochanska \& Aksan (2004) further developed the idea of mutual attunement and studied the development of infant-parent contingent interactions in naturalistic settings from 7 to 15 months of age. They discovered that as parents changed their bids communicative actions directed at their infants - over time, from mood regulation to behavior influence, children's positive bids became more frequent and physical and negative bids declined. These results illustrate the sophisticated nature of mutual attunement of socially contingent responsivity between children and caregivers. Notably, these findings also show that contingent responsivity is a social communicative mechanism driven by caregivers and infants with continuously adjusted rates and types of responses. This process of mutual adjustment might reinforce the causal link infants infer from socially contingent interactions and introduce the idea that some behaviors might be more likely to cause responses than other.

Socially contingent responsivity appears to play a critical role in infant-caregiver interactions from a very early age and to drive mutual attunement in those dyads. Because social and linguistic development vary from culture to culture and from language to language, it is possible that the sensitivity to socially contingent responsivity and the rate of response depend on the country where participants were recruited. To ensure that the development of mutually contingent responsivity is a universal phenomenon that plays a role in early development, Bornstein, Putnick, Cote, Haynes, \& Suwalsky (2015) studied maternal contingent responsivity in naturalistic settings in 11 different countries on four continents. They recruited 5.5-month-old infants and their 
mothers and recorded 1 hour of their interactions at home. Bornstein et al. reported that while there were cultural differences in rates of maternal responsivity, there was a strong general tendency among mothers to speak to their infants following non-distress (not related to hunger or discomfort) vocalizations. The authors also found that the rates of infant responsivity to mothers' vocalizations did not differ across cultures. These findings suggest that regardless of cultural environment, mother-infant dyads around the globe engage in socially contingent interactions. Despite the differences in maternal responsivity, infants' responses remained the same across cultures, suggesting that there might be some element of innateness in infant responsivity. Bornstein et al. argue that mutually contingent interactions give rise to turn taking, an essential element of social communication and learning. According to the data they present, these interactions are a universal precursor to more complex social interactions.

\subsection{Understanding the causal link between words and other events}

The reviewed empirical investigations of maternal and infant contingent responsivity suggest that (a) infants are sensitive to the levels of contingent responsivity, (b) prefer contingent over non-contingent counterparts; (c) prefer the levels of contingent responsivity that is close to their mothers' levels; (d) tend to respond to their mothers' vocalizations regardless of the rate of maternal responsivity; and (e) adjust their own rates and types of responses as parental responsivity changes. These observations lead me to hypothesize that early exposure to socially contingent interactions helps infants realize causal relations between actions of interlocutors and in cases where such interactions are verbal - realize that words have causal effect on behaviors and physical reality. These properties of socially contingent interactions facilitate infants understanding of the 
structure of social interactions and affect the development of social and communication skills in infancy. With the realization that verbal and other behaviors have causal power, infants discover that their own actions can evoke responses from others.

Several studies that investigated infants' initiation of contingent interactions and their expectations about responses illustrate my conjecture. Mcquaid, Bibok, \& Carpendale (2009) studied the relation between maternal responsivity and social expectation behavior in 4- and 5-month-olds using a still-face procedure. They found that maternal responsivity (contingent smiling) predicted infants' individual differences in smiling during the still-face phase of the procedure, which indicated that infants had expectations about social interactions and their own ability to initiate an interaction. The later finding implies that 4- and 5-month-olds already have some understanding of the causal relation between the behaviors of others and their own. While causality is not guaranteed when one event is contingent on another, it is likely that socially contingent behaviors are perceived by infants as the result of preceding behaviors of others. Infants as young as 3 months have been shown to appreciate causal relations between events (e.g., Michotte, 1963; Ball, 1973; see White (1988) for review) and may have an ability to understand causal effects of human actions (Leslie, 1982). Consistent with the findings of Mcquaid et al., Goldstein, Schwade, \& Bornstein (2009) demonstrated that 5-montholds associate their own noncry vocalizations with responses from caregivers. They used a still-face procedure to show that infants' noncry vocalizations peaked during the stillface phase, which was precede by an episode of naturalistic interaction between the experimenter and the infant. The still-face episode was followed by another episode of naturalistic interaction; during this episode the rate of noncry vocalizations significantly 
decreased showing an extinction burst. Infants' vocalization during the still-face episode can be interpreted as attempts to initiate contingent interactions with the experimenter, which provides additional evidence that infants do not only engage in contingent interactions but actively seek them. The authors concluded that by 5 months, infants already appreciate the instrumental value of their own vocalizations and that this realization might indicate the beginning of socially guided vocal learning. As the reviewed work indicates, infants in the first 6 months already possess some understanding that their behaviors are associated with responses from others. In particular, they appear to have an expectation that their vocalizations cause responses from caregivers and to actively seek socially contingent interactions by producing noncry vocalizations.

So far, I have reviewed several literatures concerning infants' learning capacities, their linguistic and social development, and infants' participation in socially contingent interactions. Empirical studies led me to suggest that until 12 months, infants' understanding of word-referent link is mostly associative. However, approaching their first birthday and early in the second year of life infants begin to realize that words are not simply paired with objects, ideas, or actions - they refer. Next, I asked if any known mechanism explains how infants transition from one state of word learning to another. From reviewing several theoretical accounts of word learning, I concluded that at the moment neither approach tells a coherent story about infant lexical learning or provides a fully specified mechanism explaining how infants transition from associative to referential understanding of words. I also reviewed several theories and models attempting to integrate sociopragmatic and associative approaches and to build a more 
comprehensive account of word learning. Most of those attempts also did not describe a mechanism underlying infants' shift towards referential word learning. Yurofsky \& Frank (2015) introduced a model, leaving a "placeholder" for a general-purpose cognitive process that facilitates such a shift. Building on this idea, I proposed that infants' engagement in socially contingent interactions launches a process that leads infants to realize that words and events in the word might be causally related. Next, I reviewed some empirical work suggesting that infants are sensitive to the level of contingency in caregiver responses and that they associate their own actions and vocalizations with responses from others. Based on this the literature review, I formulate a novel hypothesis about the role of socially contingent responsivity in referential word learning.

\subsection{The mechanism of transition to the referential understanding of words}

Expanding Goldstein et al.'s conjecture and building on the literature about infants' understanding of socially contingent interactions, I hypothesize that socially contingent responsivity plays a significant role in language acquisition, as it is a form of social learning. In concert with the emerging understanding of mental states, which is necessary to detect communicative intentions and understand the structure of social interactions, the causal link that infants infer from socially contingent responses may initiate their transition from associative to referential word learning. This transition appears to happen at around 12 months of age. If contingent responses facilitate infants' understanding of causal relations between vocalizations and responses, it is possible that infants start to use this knowledge to manipulate the behaviors of others. With sufficient exposure to different syntactic and pragmatic contexts, infants learn that words trigger the display of objects that weren't previously present, unobservable intentions or novel 
actions, which they haven't seen before. Upon reaching the understanding that people have mental states and structure their social interactions to act on those states, infants can link mental states, words and their consequences to make a leap towards appreciating the referential nature of words. Words refer to things that an agent has in mind, whether those things are present or not.

Importantly, I do not propose that referential understanding of words equates to the understanding of causality. I propose that the realization that words can cause consequences facilitates the understanding that words refer. In addition, this realization also facilitates attention to social cues during word learning, as infants understand that words are particularly relevant in social contexts and lead to social consequences. The idea of associative and social mechanisms acting in concert and complementing each other relegates my hypothesis to the family of hybrid, or coalition, approaches. While associative mechanisms could still facilitate word learning, understanding causal relations that underlie socially contingent interactions allows infants to make a leap towards linking words to mental representations of objects, actions, or mental states that they refer to.

\section{Effects of contingent responsivity on language development: empirical evidence}

In the next section of the paper, I will explore and summarize existing research on the relation between contingent responsivity and language development in infancy and early childhood. I broaden the perspective from words to language acquisition more generally because very few studies explicitly tested the effects of socially contingent 
responsivity on word learning. Broader picture may provide support to my hypothesis and valuable insights about the role of socially contingent responsivity in cognitive development. Following the review, I will propose a number of ways to operationalize and measure socially contingent responsivity as well as infants' and children's ability to appreciate the referential nature of words.

My hypothesis specifies that infants' exposure to socially contingent interactions facilitates their understanding of the causal link between words and events and, in cooperation with the developing understanding of mental states and social interactions, enables infants to transition from associative to referential word learning. My conjecture predicts that such an exposure would lead to better word learning outcomes and would potentially affect infants' social development. The latter proposition is consistent with the earlier discussion about the shift from associative to referential word learning, which appears to occur around the same time infants reach critical milestones in social development. It is possible that the proposed mechanism drives the development of both social and linguistic competences. In this paper I will limit the discussion to language development, yet I invite further speculation to shed light on the effects of socially contingent responsivity on social learning.

\subsection{Long-term effects of socially contingent responsivity on language outcomes}

Looking to establish the link between socially contingent responsivity and language outcomes, Gros-Louis, West, \& King (2014) conducted a longitudinal study where they observed 8-to-14-month-olds interact with their mothers in naturalistic settings over the course of 6 months. They found that maternal responsivity was correlated with the increase in mother-directed vocalizations. The analysis of the 
predictive relation between maternal responsivity and infant vocalizations revealed that mothers' sensitive responses were correlated with the increase in infants' mother-directed vocalizations in social interactions in the following month. In addition, mothers' imitation of infants' vocalizations also predicted mother-directed vocalizations in future months. The authors reported a significant positive correlation between maternal responsivity to mother-directed vocalizations and an increase in more mature consonantvowel vocalizations. Infants of more responsive mothers scored higher on vocabulary production measures at 15 months. The results obtained by Gros-Louis et al. indicate that maternal responses are correlated with language and communicative development in infancy and also suggest a causal link between maternal responsivity and language outcomes later in life. These findings land support to the idea that contingent responsivity facilitates word learning and might be having this effect because of the transition from associative to referential learning. While these data do not explicitly speak to the question about the transition, they do suggest that infants' social and linguistic development depends on caregivers' responsivity. Together with the results reported by Goldstein et al., this evidence supports the hypothesis that caregivers' responses drive infants' understanding of the causal link between words and events in the word. This causal relation is particularly relevant to mother-infant social interaction, which manifests in the increase in infants' vocalizations directed at their mothers.

A number of correlational and longitudinal studies highlighted the relation between parental verbal and emotional responsivity to their children during infancy with children's verbal and social competence later in life. In most cases, infant-parent dyads were observed in naturalistic environments, such as their homes. For example, Bornstein 
\& Tamis-LeMonda (1989) studied dyads of mothers and infants aged 2-5 months and assessed infants' cognitive development at ages 1 and 4. They found that maternal responsivity predicted infants' representational competence at 13 months and higher scores on Wechsler Preschool and Primary Scale of Intelligence. Further, Olson, Bates, \& Bayles (1984) reported a significant correlation between maternal responsivity, infant behaviors at 6 and 13 months, and 24-month competence outcome measures, including receptive vocabulary (Bayley MDI and PPVT). Similarly, Baumwell, Tamis-LeMonda, \& Bornstein (1997) conducted a longitudinal study tracking infants between 9 and 13 months and found that maternal responsivity at 9 months predicted infants' language comprehension at 13 months. In addition, maternal verbal responsivity at 9 months was significantly correlated with infants' language comprehension at the same age.

The reviewed studies indicate that higher rates of responses predict better developmental outcomes in various domains. These results are consistent with my hypothesis as they indicate that socially contingent responsivity contributes to language development and predicts higher verbal competence and representational abilities later in infancy. It is possible that the observed effects are related to the facilitative influence of contingent responses on infants' understanding of the referential nature of words.

\subsection{Short-term effects of socially contingent responsivity on language outcomes}

So far, the research I've talked about looked at language outcomes in the context of correlations with parental responsivity and many considered predictive relations of responsivity on vocabulary in the long term. In addition to long-term effects of socially contingent responsivity, there might be immediately observable short-term effects that may shed light on the nature of its relation to word learning. 
Contingent social responsivity has been shown to affect both phonetic perception and production in infancy. Kuhl, Tsao, \& Liu (2003) investigated 9-month-olds' ability to perceive foreign language phonetic contrast after 5 hours of exposure, split into 12 laboratory sessions over 4 weeks. While the experiment did not explicitly test the effects of socially contingent responsivity, the manipulation contrasted three groups of infants, only one of which was exposed to the foreign language in the context of socially contingent interaction. The participants were American infants acquiring English in monolingual environments. One group of infants interacted with a native speaker of Mandarin Chinese during their visits into the lab. The speaker played with the infants using toys and puppets and read children's books. The other two groups of infants were exposed to either a video, or an audio recording of the same speaker. In the case of a video recording, the speaker looked at the camera to create an impression of looking at the infant. The results showed that only infants in the live interaction condition performed above chance on the phonetic discrimination test, at the level comparable to infants acquiring Mandarin Chinese. This difference in infants' performance was likely due to the lack of contingency in video and audio exposure conditions and not due to other differences between live and recorded exposure. Kuhl et al.'s results suggest that linguistic information is better learned in the context of socially contingent interactions, which is broadly consistent with my hypothesis.

In a different study Goldstein, King, \& West (2003) researched the effects of maternal responses on infants' vocal behavior. The authors tested 8-month-olds, before they began to produce canonical sounds. Infants first engaged in a baseline interaction, when the rates of vocalizations and responsivity were established. After that, half of the 
mother-infant dyads that were assigned to the "contingent condition" continued to interact in a contingent manner; mothers were instructed to respond by smiling and touching their infants. The other half of the dyads were assigned to the "yoked condition", in which mothers were instructed to respond according to experimenter's commands, corresponding to the timing of responses in the contingent condition. During the extinction period, the dyads resumed their natural interactions. Infants in the contingent condition increased both the number and the quality of vocalizations, which had higher resemblance to English syllables, compared to the baseline. In contrast, infants in the yoked condition only increased the number of vocalizations but did not show more advanced babbling. The authors argued that their results illustrate that only socially contingent responses can induce and reinforce infants' vocal behaviors. These findings support the hypothesis that infants learn to manipulate the behaviors of others using their own vocalizations. Mutual contingency between mothers and infants resulted in a shift in infants' vocal behavior and may have facilitated infants understanding of the causal relation between their vocalizations and maternal social responses.

More recently Roseberry, Hirsh-Pasek, \& Golinkoff (2014) conducted a study that can be viewed as the most explicit test of short-term effects of socially contingent responsivity on word learning. The authors tested 2-2.5-year-olds and found that they learn new verbs equally well during a live interaction with an experimenter and during an online interaction over video chat. Toddlers in the recorded video condition with videos extracted from the video chat condition did not demonstrate successful word learning. These data indicate that the "video deficit" (Anderson \& Pempek, 2005) could result from the lack of contingent interaction. In the context of these findings, Kuhl et al.'s 
results can be interpreted as the effect of socially contingent interaction on phonetic learning.

Importantly, not just any contingent interaction can enhance children's word learning from video. DeLoache et al. (2010) found that 12-18-month-olds did not learn words presented in the video by an experimenter, if parents contingently interacted with their infants during the video exposure. They only learned the new words presented by the parents during socially contingent interactions. This suggests that contingent interactions with the source of information facilitate better learning outcomes in the verbal domain. These data can also be interpreted as evidence against the hypothesis that socially contingent responsivity acts as attentional spotlight thereby improving word learning. If this was the case, infants in DeLoache et al. study would have succeeded in learning new words when parents directed their attention to the video by interacting with them in a contingent manner. Since infants in this condition did not exhibit better knowledge of the words than infants in the control group that had no intervention, it is unlikely that socially contingent responsivity could be interpreted as a mere attentional spotlight.

Together naturalistic and laboratory investigations of the effects of socially contingent responsivity on language development suggest that children's exposure to socially contingent interactions predict better language outcomes in the long term and enhance language learning in the short term. Because experimental evidence does not support the hypothesis that socially contingent responsivity serves as an attentional spotlight, there must be different factors driving the observed effects. I conjecture that the long term predictive relation between socially contingent responsivity and language 
outcomes is the result of the transition from associative to referential word learning during the first two years of life. This transition powers word learning both because infants realize that words cause consequences and refer to things absent from their view, and because it draws infants' attention to social cues. Equipped with the sensitivities to social and distributional cues, infants map words onto their referents faster, which explains the short-term effects of socially contingent contexts. Because socially contingent responsivity increases social relevance of novel words, infants may learn them more readily, as they associate words with their referents and social consequences. In many cultures infants' attention to novel information and comprehension of novel words are rewarded (Weinberg \& Tronick, 1996) with contingent responses. Although existing studies do not provide evidence for this prediction, infant vocal behavior has been shown to depend on socially contingent responses from their mothers (Goldstein \& Schwade, 2008). These observations support the hypothesis that socially contingent responsivity indeed affects language acquisition, and word learning in particular, at multiple levels and has both short- and long-term consequences. These effects are likely due to the transition from associative to referential word learning, facilitated by infants' accumulated exposure to socially contingent interactions.

\section{Summary}

In this paper I explored the mechanisms underlying infants' transition from associative to referential word learning and mentioned infants' remarkable shift in the speed of word learning around their first birthday. I reviewed experimental evidence, models and theoretical accounts and built my hypothesis that socially contingent 
responsivity guides infants towards the realization that words refer to things. I ruled out the explanations of this transition based on perceptual and distributional cues alone because neither of the reviewed accounts provided a fully specified mechanism that would explain what exactly happens around infants' first birthday and results in their understanding of the referential nature of words. I also reviewed a number of studies indicating that children's language learning outcomes depend on the presence of socially contingent interactions earlier in infancy and even short-term word learning is significantly enhanced in socially contingent contexts. It appears that socially contingent interactions play a central role in infants' linguistic development and also affect their social development, as language is the primary medium of human communication. Some studies even suggest that socially contingent responsivity might not only guide infants' transition to referential word learning and enhance language outcomes, but also serve as a domain-general learning mechanism that allows infants to extract meaning from actions and symbol in their environment. For example, Johnson et al. (1998) showed that if 12month-olds attribute agency to entities that contingently interact with people and interpret their actions as meaningful signals. If infants have seen a scene of contingent interaction between an experimenter and an object, they followed the 'gaze' (or orientation) of that object even if it is amorphously shaped and has nothing resembling a face. A different study by Lohaus, Lissmann, Ball, Borke, \& Lamm (2005) examined infants' ability to detect non-social contingencies found that infants whose mothers provided more social contingency were more likely to detect non-social contingencies in their environment (e.g., mobile moves when infant kicks). 
In my review I searched for evidence that infants transition from associative to referential word learning and that perceptual and associative mechanisms cannot fully explain this transition. I also looked for evidence that infants are sensitive to socially contingent responsivity and that it is related to infants' success in language learning, specifically learning of novel words. I built my argument based on the existing studies. However, my hypothesis requires explicit testing in order to conclude that socially contingent responsivity indeed drives infants' understanding of the referential nature of words and that it might also facilitate reaching the milestones of social development that tend to co-occur with this transition. In order to design experiments that would test my hypothesis, it is important to provide an operational definition of socially contingent responsivity. So far, the studies I've reviewed all used somewhat different operational definitions, ranging from maternal responsiveness to non-distress vocalizations to social feedback to presence or absence of any online exchanges between an infant or a child and an adult. In addition, a large proportion of such studies examined the effects of maternal responsivity on infants' learning, which is a limitation of such studies in the context of my hypothesis, as I do not limit the effects of socially contingent interactions to interactions with mothers or caregivers. In the next section of my paper I will provide a brief review of operational definitions of socially contingent responsivity that I have encountered and synthesize my definition that I will use to test my hypothesis.

\section{Theoretical construct}

From the beginning of the paper, I have been referring to the construct as "socially contingent responsivity". I borrowed the term "contingent responsivity" from 
Csibra (2010), who listed it as one of ostensive communicative signals, to which infants are sensitive from a very early age. This name was chosen to reflect the defining aspects of this set of behaviors. First, socially contingent responsivity implies that responses are produced in the context of a social interaction. If an adult produces actions contingent on their infant's behavior, but those actions are not directed at the infant, such as closing the door following the infant's sneezing, those actions would not be described as socially contingent. Within my construct, I focus on actions that signal infant-directedness using gaze direction, infant-directed speech, sharing a locus of joint attention, touching, or approaching an infant following his or her actions. Similarly, infants' actions should be considered socially contingent if the infant directs his or her gaze at the interlocutor, attempts to direct the interlocutor's attention, touches, or approaches the interlocutor. Self-directed play and exploration would not be considered social within this framework. Second, my construct implies that actions of infants and their interlocutors are contingent on the preceding behaviors of the interaction partner. To determine which behaviors should be considered contingent, I review a few studies previously mentioned in the paper.

The majority of investigations have put emphasis on the timing of responses in order to determine whether such responses were contingent. In most cases, the time window between infants' and adults' behaviors was chosen to be 1 second as a criterion of contingency (Bigelow, 1996; Bigelow \& Rochat, 2006; Bigelow \& Power, 2014; Kochanska \& Aksan, 2004; Lohaus et al., 2005). In a number of experiments, the time window was longer: 2 seconds (Mcquaid et al., 2009; Bornstein et al., 2015; Gros-Louis, West, \& King, 2014) or 5 seconds (Baumwell, Tamis-LeMonda, \& Bornstein, 1997; 
Olson, Bates, \& Bayles, 1984) following infants' actions. In some cases, the time window used as a criterion of contingency was not specified (Goldstein, King, \& West, 2003; Bornstein \& Tamis-LeMonda, 1989). In the latter case, contingency was qualitatively defined as temporarily and semantically contiguous action directed at an infant.

In addition to specifying the time window, several investigations restricted the types of infant behaviors triggering adult responses. Such behaviors included smiles and vocalizations (Bigelow \& Rochat, 2006; Mcquaid et al., 2009; Bornstein et al., 2015), where vocalizations sometimes were restricted to non-distress (Bigelow \& Power, 2014) or positive (Kochanska \& Aksan, 2004) and directed at objects or interlocutors (Baumwell, Tamis-LeMonda, \& Bornstein, 1997; Gros-Louis, West, \& King, 2014). Adults' responses were also restricted to a set of behaviors considered appropriate reactions to infants' bids. In some studies, such behaviors included smiles, vocalizations and facial expressions (Bigelow, 1996; Bigelow \& Rochat, 2006; Bigelow \& Power, 2014; Mcquaid et al., 2009; Bornstein et al., 2015). Other studies also included verbal acknowledgements or directives, moves towards infants and touches, and verbal imitations (Bornstein \& Tamis-LeMonda, 1989; Baumwell, Tamis-LeMonda, \& Bornstein, 1997; Goldstein, King, \& West, 2003; Kochanska \& Aksan, 2004; Lohaus et al., 2005; Gros-Louis, West, \& King, 2014). Contingent responses of both infants and adults were used to calculate a number of quantitative measures, including rates of responses, their frequency and probability.

Unlike the time criteria that were used to determine whether a given behavior is contingent of the behavior of the other party, the reviewed articles have much less 
agreement with regard to the types of behaviors they've chosen to code. These responses vary both in terms of types of behavior and its complexity. While some studies classify maternal responses into smiles, touches and vocalizations, others include the details about the types of utterance or forms of object manipulation. In some cases, the divergence in method can be justified with the differences in the research question. I propose that a more standardized and comprehensive measures would benefit future investigations of socially contingent responsivity and its effects on development, however, developing such an inventory goes beyond the scope of my paper.

I propose that my construct should include behaviors produced by adults following infants' non-distress vocalizations. Because my question is about word learning and understanding that words refer, I do not include other types of infant behaviors and distress vocalizations. I also propose that most behaviors produced by adult interlocutors should be included in my construct as long as they meet the criteria of being directed at an infant, which I mentioned earlier. In my view, the time window used as a contingency criterion can be extended to $1-5 \mathrm{~s}$ following infants' vocalizations. Although most of the reviewed studies chose 1-2-s intervals, I hypothesize that in naturalistic environments where infants interact with adults outside the lab space, adults might be slower to respond to their infants, as they may be farther away from their infants or preoccupied with work responsibilities, which would slow them down. With this construct in mind, I can develop experimental tests of my hypothesis to determine whether socially contingent responsivity indeed facilitates the transition from associative to referential word learning. 


\section{Limitations}

It's important to note that my theoretical proposition has a number of limitations. My hypothesis relies on the proposition that infants begin to understand the referential nature of words as they master the causal link between verbal behaviors and their consequences. However, words as references do not cause objects to appear or actions to be produced. Words refer to the mental representations of events, phenomena and physical entities in my environment. In order to develop a mature understanding of words as references infants must eventually decouple them from the causal link. My paper does not address how this process occurs. The scope of this work outlines the process that triggers infants' realization that words have causal power over infants' social environment, prompting actions, emotional reactions and verbal exchanges. Infants notice that utterances including names of objects lead to those objects being retrieved with some probability. They also notice that utterances including directives may lead to certain actions. By the time children approach age 2, they do not only have such expectations but also can have a conversation about objects, actions and ideas. My paper does not explain how this process unfolds. It might be that understanding the referential nature of words, coupled with explicit labeling and cross-situational learning based on distributional cues help infants abstract from the contexts in which they initially encounter words as references. At the same time, increasing memory capacity and conceptual learning, which I also left outside the scope of my discussion, facilitate children's ability to refer to their own mental representations in speech. Because children's representational abilities and theory of mind reach important milestones around 12 months, infants may develop an 
understanding that other people have similar mental images as their own. Such an understanding could drive further development of referential word learning and word use.

In conclusion, I would like to emphasize that my hypothesis describes the transition from associative to referential word learning with the help of causal cues available in socially contingent interactions. I do not propose that associative and perceptual mechanisms cease to facilitate word learning in the post-transition period or receive less weight. I believe that word learning relies on multiple mechanism working simultaneously to produce the observed developmental outcomes. 


\section{References}

Akhtar, N., \& Tomasello, M. (1998). Intersubjectivity in early language learning and use. Intersubjective communication and emotion in early ontogeny, 316-335.

Anderson, D. R., \& Pempek, T. A. (2005). Television and very young children. American Behavioral Scientist, 48(5), 505-522.

Ball, W. A. (1973, April). The perception of causality in the infant. In meeting of the Society for Research in Child Development, Philadelphia, PA.

Baumwell, L., Tamis-LeMonda, C. S., \& Bornstein, M. H. (1997). Maternal verbal sensitivity and child language comprehension. Infant Behavior and Development, $20(2), 247-258$.

Bergelson, E., \& Swingley, D. (2012). At 6-9 months, human infants know the meanings of many common nouns. Proceedings of the National Academy of Sciences, 109(9), 3253-3258.

Bergelson, E., \& Swingley, D. (2015). Early Word Comprehension in Infants: Replication and Extension. Language Learning and Development, 11(4), 369-380.

Bigelow, A. E. (1996). Infants' memory for contingently responding persons. Infant Behavior and Development, 19, 334.

Bigelow, A. E., \& Power, M. (2014). Effects of Maternal Responsiveness on Infant Responsiveness and Behavior in the Still-Face Task. Infancy, 19(6), 558-584.

Bigelow, A. E., \& Rochat, P. (2006). Two-month-old infants' sensitivity to social contingency in mother-infant and stranger-infant interaction. Infancy, 9(3), 313325. 
Bornstein, M. H., \& Tamis-LeMonda, C. S. (1989). Maternal responsiveness and cognitive development in children. New Directions for Child and Adolescent Development, 1989(43), 49-61.

Bornstein, M. H., Putnick, D. L., Cote, L. R., Haynes, O. M., \& Suwalsky, J. T. (2015). Mother-Infant Contingent Vocalizations in 11 Countries. Psychological Science, 0956797615586796.

Carpenter, M., Nagell, K., Tomasello, M., Butterworth, G., \& Moore, C. (1998). Social cognition, joint attention, and communicative competence from 9 to 15 months of age. Monographs of the Society for Research in Child Development, i-174.

Chomsky, N. (2014). Aspects of the Theory of Syntax (Vol. 11). MIT press.

Csibra, G. (2010). Recognizing communicative intentions in infancy. Mind \& Language, $25(2), 141-168$.

Csibra, G., \& Gergely, G. (2009). Natural pedagogy. Trends in cognitive sciences, 13(4), $148-153$.

De Saussure, F. (2011). Course in General Linguistics [1916]. New York, NY: Columbia University Press.

Deacon, T. (1997). The symbolic species.

DeCasper, A. J., \& Fifer, W. P. (1980). Of human bonding: Newborns prefer their mothers' voices. Science, 208(4448), 1174-1176.

DeCasper, A. J., \& Spence, M. J. (1986). Prenatal maternal speech influences newborns' perception of speech sounds. Infant Behavior and Development, 9(2), 133-150.

Dehaene-Lambertz, G., Dehaene, S., \& Hertz-Pannier, L. (2002). Functional neuroimaging of speech perception in infants. Science, 298(5600), 2013-2015. 
DeLoache, J. S., Chiong, C., Sherman, K., Islam, N., Vanderborght, M., Troseth, G. L., Strouse, G. A., \& O’Doherty, K. (2010). Do babies learn from baby media? Psychological Science.

DeLoache, J. S., Strauss, M. S., \& Maynard, J. (1979). Picture perception in infancy. Infant Behavior and Development, 2, 77-89.

Eimas, P. D., Siqueland, E. R., Jusczyk, P., \& Vigorito, J. (1971). Speech perception in infants. Science, 171(3968), 303-306.

Eimas, P. D. (1975). Developmental studies in speech perception. Infant perception: From sensation to cognition, 2, 193-231.

Engelhardt, R. (2007). Dynamical aspects of the Origin and Evolution of Language. In Language and Prehistory of the Indo-European Peoples - a Crossdisciplinary Perspective.

Evans, N., \& Levinson, S. C. (2009). The myth of language universals: Language diversity and its importance for cognitive science. Behavioral and Brain Sciences, $32(05), 429-448$.

Ferry, A. L., Hespos, S. J., \& Waxman, S. R. (2010). Categorization in 3-and 4-monthold infants: an advantage of words over tones. Child Development, 81(2), 472479.

French, R. M., Mareschal, D., Mermillod, M., \& Quinn, P. C. (2004). The role of bottomup processing in perceptual categorization by 3-to 4-month-old infants: simulations and data. Journal of Experimental Psychology: General, 133(3), 382.

Gergely, G., Nádasdy, Z., Csibra, G., \& Bíró, S. (1995). Taking the intentional stance at 12 months of age. Cognition, 56(2), 165-193. 
Gliga, T., \& Csibra, G. (2009). One-year-old infants appreciate the referential nature of deictic gestures and words. Psychological Science, 20(3), 347-353.

Gliozzi, V., Mayor, J., Hu, J. F., \& Plunkett, K. (2008, January). The impact of labels on visual categorisation: A neural network model. In Proceedings of the Annual Meeting of the Cognitive Science Society (Vol. 30, No. 30).

Goldstein, M. H., \& Schwade, J. A. (2008). Social feedback to infants' babbling facilitates rapid phonological learning. Psychological Science, 19, 515-523

Goldstein, M. H., King, A. P., \& West, M. J. (2003). Social interaction shapes babbling: Testing parallels between birdsong and speech. Proceedings of the National Academy of Science of the United States of America, 100, 8030-8035.

Goldstein, M. H., Schwade, J. A., \& Bornstein, M. H. (2009). The Value of Vocalizing: Five-Month-Old Infants Associate Their Own Noncry Vocalizations With Responses From Caregivers. Child Development, 80(3), 636-644.

Golinkoff, R. M., Hirsh-Pasek, K., Bloom, L., Smith, L. B., Akhtar, N., Tomasello, M., \& Hollich, G. (2000). Becoming a word learner: A debate on lexical acquisition. Oxford University Press.

Gros-Louis, J., West, M. J., \& King, A. P. (2014). Maternal responsiveness and the development of directed vocalizing in social interactions. Infancy, 19(4), 385-408.

Hauser, M. D., Chomsky, N., \& Fitch, W. T. (2002). The faculty of language: what is it, who has it, and how did it evolve? Science, 298(5598), 1569-1579.

Hirsch-Pasek, K., Golinkoff, R. M., \& Hollich, G. (2000). An emergentist coalition model for word learning. Becoming a Word Learner: A Debate on Lexical Acquisition, 136-164. 
Hollich, G. J., Hirsh-Pasek, K., Golinkoff, R. M., Brand, R. J., Brown, E., Chung, H. L., Hennon, E., Rocroi, C., \& Bloom, L. (2000). Breaking the language barrier: An emergentist coalition model for the origins of word learning. Monographs of the society for research in child development, i-135.

Hurford, J. R. (1989). Biological evolution of the Saussurian sign as a component of the language acquisition device. Lingua, 77(2), 187-222.

Johnson, S. C. (2000). The recognition of mentalistic agents in infancy. Trends in Cognitive Sciences, 4(1), 22-28.

Jusczyk, P. W., \& Hohne, E. A. (1997). Infants' memory for spoken words. Science, 277(5334), 1984-1986.

Kaminski, J., Call, J., \& Fischer, J. (2004). Word learning in a domestic dog: evidence for “fast mapping”. Science, 304(5677), 1682-1683.

Kaye, K. (1977). Toward the origin of dialogue. Studies in mother-infant interaction, 89117.

Kochanska, G., \& Aksan, N. (2004). Development of mutual responsiveness between parents and their young children. Child Development, 75, 1657-1676.

Kuhl, P. K., Tsao, F. M., \& Liu, H. M. (2003). Foreign-language experience in infancy: Effects of short-term exposure and social interaction on phonetic learning. Proceedings of the National Academy of Sciences, 100(15), 9096-9101.

Leslie, A. M. (1982). The perception of causality in infants. Perception, 11(2), 173-186.

Lohaus, A., Keller, H., Lissmann, I., Ball, J., Borke, J., \& Lamm, B. (2005). Contingency experiences of 3-month-old children and their relation to later developmental achievements. The Journal of Genetic Psychology, 166(4), 365-383. 
Lyn, H., \& Savage-Rumbaugh, E. S. (2000). Observational word learning in two bonobos (Pan paniscus): Ostensive and non-ostensive contexts. Language \& Communication, 20(3), 255-273.

Mandel, D. R., Jusczyk, P. W., \& Pisoni, D. B. (1995). Infants' recognition of the sound patterns of their own names. Psychological Science, 6(5), 314.

Martin, A., Onishi, K. H., \& Vouloumanos, A. (2012). Understanding the abstract role of speech in communication at 12 months. Cognition, 123, 50-60.

Masataka, N. (2003). The onset of language (Vol. 9). Cambridge University Press.

Mattys, S. L., Jusczyk, P. W., Luce, P. A., \& Morgan, J. L. (1999). Phonotactic and prosodic effects on word segmentation in infants. Cognitive Psychology, 38(4), 465-494.

McMurray, B., Horst, J. S., \& Samuelson, L. K. (2012). Word learning emerges from the interaction of online referent selection and slow associative learning. Psychological Review, 119(4), 831.

Mcquaid, N. E., Bibok, M. B., \& Carpendale, J. I. (2009). Relation between maternal contingent responsiveness and infant social expectations. Infancy, 14(3), 390-401.

Michotte, A. (1963). The perception of causality.

Nazzi, T., \& Bertoncini, J. (2003). Before and after the vocabulary spurt: two modes of word acquisition? Developmental Science, 6(2), 136-142.

Nazzi, T., \& Ramus, F. (2003). Perception and acquisition of linguistic rhythm by infants. Speech Communication, 41(1), 233-243.

Nelson, K. (1988). Constraints on word learning? Cognitive Development, 3(3), 221-246. 
Olson, S. L., Bates, J. E., \& Bayles, K. (1984). Mother-infant interaction and the development of individual differences in children's cognitive competence. Developmental Psychology, 20(1), 166.

Parise, E., \& Csibra, G. (2012). Electrophysiological evidence for the understanding of maternal speech by 9-month-old infants. Psychological Science, 23(7), 728-733.

Pavlov, I. P. (1927). Conditioned reflexes. An Investigation of the physiological activity of the cerebral cortex.

Plunkett, K., Hu, J. F., \& Cohen, L. B. (2008). Labels can override perceptual categories in early infancy. Cognition, 106(2), 665-681.

Plunkett, K., Sinha, C., Møller, M. F., \& Strandsby, O. (1992). Symbol grounding or the emergence of symbols? Vocabulary growth in children and a connectionist net. Connection Science, 4(3-4), 293-312.

Pruden, S. M., Hirsh-Pasek, K., Golinkoff, R. M., \& Hennon, E. A. (2006). The Birth of Words: Ten-Month-Olds Learn Words Through Perceptual Salience. Child Development, 77(2), 266-280.

Regier, T. (2005). The emergence of words: Attentional learning in form and meaning. Cognitive Science, 29(6), 819-865.

Roseberry, S., Hirsh-Pasek, K., \& Golinkoff, R. M. (2014). Skype me! Socially contingent interactions help toddlers learn language. Child Development, 85(3), 956-970.

Saffran, J. R., Aslin, R. N., \& Newport, E. L. (1996). Statistical learning by 8-month-old infants. Science, 274(5294), 1926-1928. 
Saffran, J. R., Johnson, E. K., Aslin, R. N., \& Newport, E. L. (1999). Statistical learning of tone sequences by human infants and adults. Cognition, 70(1), 27-52.

Shi, R., Werker, J. F., \& Morgan, J. L. (1999). Newborn infants' sensitivity to perceptual cues to lexical and grammatical words. Cognition, 72(2), B11-B21.

Shukla, M., White, K. S., \& Aslin, R. N. (2011). Prosody guides the rapid mapping of auditory word forms onto visual objects in 6-mo-old infants. Proceedings of the National Academy of Sciences, 108(15), 6038-6043.

Shultz, S., \& Vouloumanos, A. (2010). Three-month-olds prefer speech to other naturally occurring signals. Language Learning and Development, 6, 241-257.

Smith, L. B., Suanda, S. H., \& Yu, C. (2014). The unrealized promise of infant statistical word-referent learning. Trends in Cognitive Sciences, 18(5), 251-258.

Sobel, D. M., \& Kirkham, N. Z. (2006). Blickets and babies: the development of causal reasoning in toddlers and infants. Developmental Psychology, 42(6), 1103.

Surian, L., Caldi, S., \& Sperber, D. (2007). Attribution of beliefs by 13-month-old infants. Psychological Science, 18(7), 580-586.

Syal, S., \& Finlay, B. L. (2011). Thinking outside the cortex: social motivation in the evolution and development of language. Developmental Science, 14(2), 417-430.

Tomasello, M. (1992). The social bases of language acquisition. Social Development, $1(1), 67-87$.

Vouloumanos, A., \& Werker, J. F. (2004). Tuned to the signal: the privileged status of speech for young infants. Developmental Science, 7(3), 270-276.

Vouloumanos, A., \& Werker, J. F. (2007). Listening to language at birth: Evidence for a bias for speech in neonates. Developmental Science, 10(2), 159-164. 
Vouloumanos, A., Onishi, K. H., \& Pogue, A. (2012). Twelve-month-old infants recognize that speech can communicate unobservable intentions. Proceedings of the National Academy of Sciences USA, 109(32), 12933-12937.

Vygotsky, L. S. (1962). Thought and language (1934). Trans. Eugenia Hanfmann and Gertrude Vakar. Cambridge, MA: MIT P.

Waxman Sandra, R., \& Markow Dana, B. (1995). Words as invitations to form categories: Evidence from 12-to 13-month-old infants. Cognitive Psychology, 29(3), 257-302.

Waxman, S. R., \& Gelman, S. A. (2009). Early word-learning entails reference, not merely associations. Trends in Cognitive Sciences, 13(6), 258-263.

Weinberg, M. K., \& Tronick, E. Z. (1996). Infant Affective Reactions to the Resumption of Maternal Interaction after the Still-Face. Child Development, 67(3), 905-914.

Werker, J. F., Cohen, L. B., Lloyd, V. L., Casasola, M., \& Stager, C. L. (1998). Acquisition of word-object associations by 14-month-old infants. Developmental Psychology, 34(6), 1289.

White, P. A. (1988). Causal processing: Origins and development. Psychological Bulletin, 104(1), 36.

Woodward, A. L., Markman, E. M., \& Fitzsimmons, C. M. (1994). Rapid word learning in 13-and 18-month-olds. Developmental Psychology, 30(4), 553.

Xu, F., Cote, M., \& Baker, A. (2005). Labeling guides object individuation in 12-monthold infants. Psychological Science, 16(5), 372-377.

Yu, C., \& Ballard, D. H. (2007). A unified model of early word learning: Integrating statistical and social cues. Neurocomputing, 70(13), 2149-2165. 
Yurovsky, D., \& Frank, M. C. (2015). Beyond naïve cue combination: salience and social cues in early word learning. Developmental Science, 20(2). 